Analytical Methods in Environmental Chemistry Journal Vol 2 (2019) 63-72

Research Article, Issue 1
Analytical Methods in Environmental Chemistry Journal
AMECJ

\title{
Synthesis and performance of graphene and activated carbon composite for absorption of three-valance arsenic from wastewater
}

\author{
Ahmad Ghozatloo ${ }^{\mathrm{a}, \mathrm{*}}$, Amir Zarei a,b and Mojtaba Arjomandi c,d \\ ${ }^{a}$ Research Institute of Petroleum Industry, Tehran, Iran, Postal Box 14765-1376 \\ ${ }^{b}$ Department of Analytical chemistry, Payam Noor university, Kerman, Iran/ Department of Analytical chemistry Science and Research Branch, Islamic \\ Azad University, Tehran, Iran \\ c Department of Water Sciences and Engineering, Science and Research Branch, Islamic Azad University, Tehran, Iran/ Research Institute of Petroleum \\ Industry (RIPI), Tehran, Iran \\ ${ }^{d}$ Department of Geophysics and Hydrogeology, Geological Survey and Mineral Explorations of Iran (GSI), Tehran, Iran
}

A R T I C L E I N F O:

Received 4 Dec 2019

Revised form 8 Feb 2019

Accepted 1 Mar 2019

Available online 21 Mar 2019

Keywords:

Arsenic

Graphene

Activated carbon

Adsorption

Acidity of wastewater

\begin{abstract}
A B S T R A C T
The presence of high levels of arsenic in the effluent is a major concern of human, and the removal of it from the wastewater is hard and costly. The most common techniques for removal of arsenic are membrane separation, ion exchange, oxidation, and coagulation. All of these technologies eventually lead to the separation of arsenic from wastewater and its accumulation among absorbent materials, which are precipitated as sludge or extracted from liquid intermediate phase. In this adsorption method, materials such as active alumina, active carbon, titanium oxide, silicon oxide, and many natural and artificial elements are used. Considering that active carbon is used as the most common arsenic adsorbent in wastewater treatment processes, this study has been considered as the main adsorbent and attempted to improve its surface properties by graphene nanosheets. Thus, by adding $4.5 \mathrm{w} . \%$ graphene to the carbon structure, its porosity increases, and the ion exchange behavior and surface load are corrected. In this research, the effects of time process, concentration of arsenic, and adsorbent are evaluated in different $\mathrm{pH}$ values. It has been observed that the maximum adsorption of arsenic is $91.8 \%$; in addition, when graphene is used, the rate of absorption of Arsenic has increased about $5.2 \%$, and the process time is shortened. In addition, using graphene is cost-effective. It is also observed that the efficiency of the adsorption process increases near neutral $\mathrm{pH}$ values; therefore, the adsorption method by graphene/activated carbon composite in neutral cells can be used as an additional method for industrial wastewater treatment.
\end{abstract}

\section{1- Introduction}

Nowadays, five major and hazardous pollutants which can pollute and threaten drinking water, groundwater, urban water, and bottled water are known. The pollutants are arsenic, lead, fluoride, chromium, and radioactive substances. Due to the impossibility of biodegradation of arsenic in the environment, it remains in contaminated water, and thereby, it is considered as one of the most

\footnotetext{
*Corresponding Author: Ahmad Ghozatloo

E-mail: ghozatlooa@ripi.ir

DOI: https://doi.org/10.24200/amecj.v2.i01.53
}

hazardous pollutants in wastewaters and water resources. In addition, the tendency of arsenic to accumulate in the members of the body causes dangerous diseases and cancers. The effects of arsenic on the liver and nervous networks are very prominent and cause a delay in mental activity and anemia. In addition, arsenic enters in the water, irrigated water, and environment in various ways such as mining, printing, and reproduction industries, petrochemical complexes, and chemical industries or as a pollutant in their effluent. According to available standards for drinking water, the limit for arsenic is up to $10 \mathrm{ppm}$ 
[1]. There are various methods for the adsorption or removal of arsenic from contaminated water sources, the most important of which are chemical deposition [2], reduction by electron ultrafiltration [3], ion exchange [4], and absorption process [5]. Among these approaches, the absorption method is more cost-effective, efficient, and easy-to-absorb, and extensive studies on the absorption of arsenic by adsorption processes have been reported [7-5]. However, researches are looking for adsorbents with a higher absorption rate, the identification of an ideal adsorbent for the maximum absorption of arsenic has not yet been suggested clearly. Activated carbon has been used with the proper properties as an efficient absorbent in treatment of industrial wastewater for a Long time, especially in the absorption of metal ions. In the meantime, various technologies, including nanotechnology, have increased the capacity of adsorbents used to absorb more pollutants, including arsenic, so that a new view has been opened in the field of wastewater treatment. For example, carbon nanotubes [8], graphene [9], graphene-oxide [10], various graphene base materials, including graphene hybrids [11] and graphene/metal oxide nanocomposites [12], including nano-absorbents which have been used in extensive researches, and by using them, the best results have been obtained. Moreover, no information is available to use the adsorption of graphene/activated carbon for removing arsenic from wastewaters. Graphene oxide has shown good results in the removal of some heavy metals from the effluent, which, in its structure, oxygen acts as an absorption agent for metal ions [13]. In graphene/activated carbon composite, each of graphene and activated carbon structures exhibits distinct effects on each other's performance. For example by considering the effect of activated carbon on graphene behavior, it can be admitted that the layer of graphene plate is rolled onto activated carbon that not only prevents the graphene from sticking together, but also increases the porosity of the composite structure. Consequently, it increases the specific surface of adsorbents, which it is ideal target for sorbents.
On the other hand, graphene sheets, due to their very small structures, act as a filler among the active carbon structures and due to its conductive behavior, and thereby, the absorption path in the new structure of activated carbon is shortened. It also facilitates the transfer of free electrons in the composite structure and lowers its resistance. This phenomenon is also the ideal goal of an ideal adsorbent in sorption of ions [14]. In this research, the graphene/activated carbon composite synthesized as a porous adsorbent with a high specific surface area is used for absorbing arsenic from industrial effluent.

\section{Experimental}

\subsection{Synthesis of Activated carbon/graphene composite absorbent}

At First, graphene oxide has been obtained by Hammers method with the mechanism of opening of graphite layer sheets. After that, a double layer dish with dilute sulfuric acid is washed, and while the solution of sulfuric acid including graphite is stirred, the temperature of the solution is reached to $0{ }^{\circ} \mathrm{C}$ using liquid cooling circulator. The amount of $2300 \mathrm{ml}$ of sulfuric acid (98\%) has been poured into the reactor and mixed with $100 \mathrm{~g}$ of pure graphite powder into the container, and the mixing operation has been carried out for 30 minutes. Afterwards, the amount of $300 \mathrm{~g}$ of solid potassium permanganate powder is slowly added to the mixture during 6 hours, and the mixture is stirred for one hour after completion. Then the temperature circulator is increased to $40{ }^{\circ} \mathrm{C}$, and after stabilizing the temperature, the mixing operation continuous for about three hours. For dilution, $500 \mathrm{ml}$ of distilled water is added with caution to the reactor, and the circulator bleach and 3.5 liters of distilled water are poured into a larger container, and then the contents of the reactor are slowly transferred to a larger container. Afterwards, the mixing operation is carried out for one hour. The amount of $300 \mathrm{ml}$ hydrogen peroxide $30 \%$ has been slowly added to the container, then mixing condition has continued for 2 hours. Then 3 liters of chloride acid have been added to 3 liters of distilled water separately. 
Afterwards, the produced solution has been added to the contents of the container. Then the process continues for one hour. The stirrer has been turned off, and the mixture has been subjected to the intense ultrasound waves for 4 hours since the opened plates do not adhere to each other. After that, the container has been settled about eight hours until the sediment is formed. Then from the above part of the container, the produced solution has been poured out, and the sediment contents of the container are filtered. The strained cake is transferred to a Chinese plant. Afterwards, the cake is placed in a vacuum oven at $50{ }^{\circ} \mathrm{C}$ for two hours, and then rinsed ultrasonically with distilled water until neutral $\mathrm{pH}$ is achieved. After the neutralization process, the powder formed is used as the graphene oxide [15]. To prepare activated carbon, first $200 \mathrm{~g}$ of powdered glucose is placed into a quartz tube. The reactor is placed under nitrogen atmosphere for 30 minutes. It is then gently warmed up to a temperature of $350{ }^{\circ} \mathrm{C}$ and remained for 2 hours. The glucose is carbonized under these conditions and is colored as a black powder. In order to increase the activated carbon efficiency, its surface activation is carried out to perform a graphene composite synthesis reaction under a two-step preactivation process. In the first step, at first, $10 \mathrm{~g}$ of activated carbon powder is mixed with $20 \mathrm{~g}$ of zinc chloride, and the mixed composite powder is added to $300 \mathrm{ml}$ of distilled water in a closed container. Afterwards, the produced solution is exposed to heat for 7 hours at $70{ }^{\circ} \mathrm{C}$. During the heating process, the water must not evaporate, and the process is carried out in a dilute aqueous medium. This action causes the activated carbon to become more porous. Then, the mixture becomes smooth with a filter paper, and the smooth mixture is dried in an oven at $80^{\circ} \mathrm{C}$ for 1 hour. The dried powder is placed in a tubular quartz reactor, and the powder is heated for one hour under neutral atmosphere while temperature is equal to $400{ }^{\circ} \mathrm{C}$. The powder has been extracted from the reactor. Then the powder has been poured into a one-molar chloride acid at $90{ }^{\circ} \mathrm{C}$ for 30 minutes. This has been carried out to remove chloride from the remaining activated carbon powder. The remaining mixture is filtered and washed with warm distilled water several times to remove remaining and additional chemicals. The filter cake is dried in an oven at $65^{\circ} \mathrm{C}$ for 11 hours. In the second step, $10 \mathrm{~g}$ of the carbon powder obtained from the first step has been mixed with 30 $\mathrm{g}$ of potassium hydroxide, and the obtained mixture has been placed in $300 \mathrm{ml}$ of distilled water into the container and brought to a temperature of $50{ }^{\circ} \mathrm{C}$. Then the mixture is mixed with alternating heat for 1 hour. The resulting mixture has been filtered with filter paper. Afterwards, the filtered mixture has been dried in an oven that its temperature is equal to $80^{\circ} \mathrm{C}$ for 1 hour. The dried powder is placed in a tube quartz reactor and heated slowly at $700^{\circ} \mathrm{C}$ for one hour under neutral atmospheres. The powder has been brought out from the reactor. Afterwards, it has been dried in an oven at $40{ }^{\circ} \mathrm{C}$ for one night. Dried powder is a porous activated carbon that is susceptible to participation in the graphene composite structure. In order to synthesize the active graphene / activated carbon composite, first add 0.9 grams of dried graphene powder to 200 $\mathrm{ml}$ distilled water and add ultrasonic waves of 100 watts for a period of two hours, which appears as a mixed mustard mixture. Then, the amount of 20 grams of activated carbon powder is slowly added to the ultrasonic mixture for 3 hours. The mixture is placed at $50{ }^{\circ} \mathrm{C}$ for one day, and then the water evaporates. The remaining solids are introduced into a quartz reactor formed in a tube, and under a nitrogen atmosphere, it is slowly heated to 350

${ }^{\circ} \mathrm{C}$ and left for 2 hours. The final product of this reactor is the graphene/activated carbon composite [16].

\subsection{Study of structural properties of graphene/ activated carbon composite}

In order to investigate the crystalline structure and the phases present in the synthesized graphene/ carbon composite, X-ray analysis has been carried out. In this study, a XRD spectrometer (Philips, PW-1840) with a beam of $1.494 \mathrm{~nm}$ and a voltage of $40 \mathrm{kV}$ and a current of $30 \mathrm{~mA}$ has been used. The spectrum obtained has been compared with 
the Hammers graphene XRD. This comparison is shown in Figure 1.

According to Fig. 1 (a), it is seen that the graphene obtained from the Hammer's process at 12.5 degrees has a sharp and narrow peak, which indicates the crystalline structure of the graphene oxide form, this means that the process of opening graphite plates in the reaction of oxidation with concentrated acid (Hammers process) is successfully achieved. While in Figure 1 (b), the peak has been shifted to a point of 26.5 degrees and its intensity is very low. This criterion is a carboncrystalline structure with double bonds without the presence of oxygenation groups, which has been observed in pure graphene structure. As a result, the process of making the graphene/activated carbon composite, which has undergone a severe

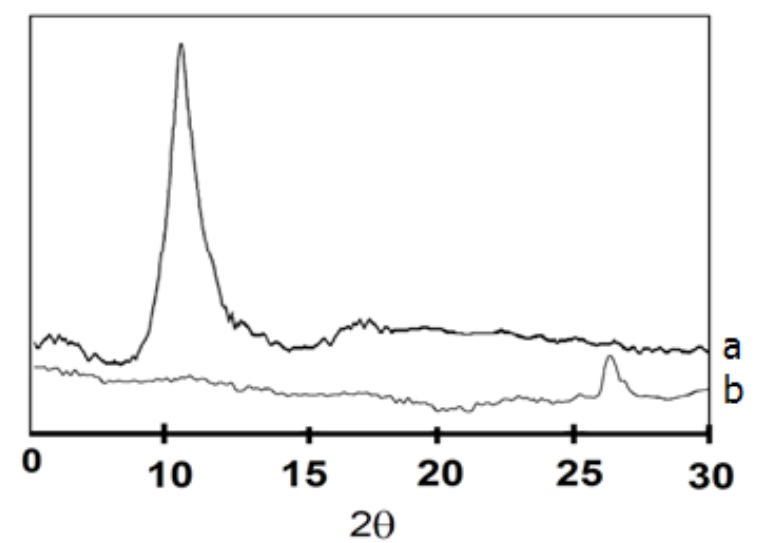

Fig. 1. XRD spectrum of graphene / activated carbon composite heat stroke, causes the oxygen groups have been removed from the composite structure. It also shows that the synthesized composite structure is free of any non-carbon bonding, in other words, there is no additional contaminant in its structure. In the following, a comparison of the two types of graphite and synthesized composites is made, as seen in Figure 2.

It is observed that the peaks of D and $G$ in the area of cm-1 of 1338 and $1611 \mathrm{~cm}-1$ appear to be good in this function respectively. The D-peak represents structural defects that appear due to its presence in destructive environments such as concentrated (or s trong) acidic environments or the presence of different operating groups on the graphene's structural surface, while the G-peak is due to the grap $\mathrm{h}$ ite crystalline network produced by the carbon bonds. Thus, the ratio of the intensity of the $\mathrm{D} / \mathrm{G}$ peaks is an indicator of the structural state of graphene, which is equal to 0.88 , as shown in Fig. 2a. This ratio indicates the presence of high oxygen groups on the structure of the Hammers graphene, while in Fig. 2b, this value is increased to 1.69 due to the elimination of oxygen's groups of the present graphene in the destructive environment. Thes e results are also consistent with the XRD analy sis shown in Fig. 1. In order to study the surf a ce properties of graphene/activated carbon composite, the TEM image has been used, as seen in Fig. 3. According to Fig. 3, it can be seen that the

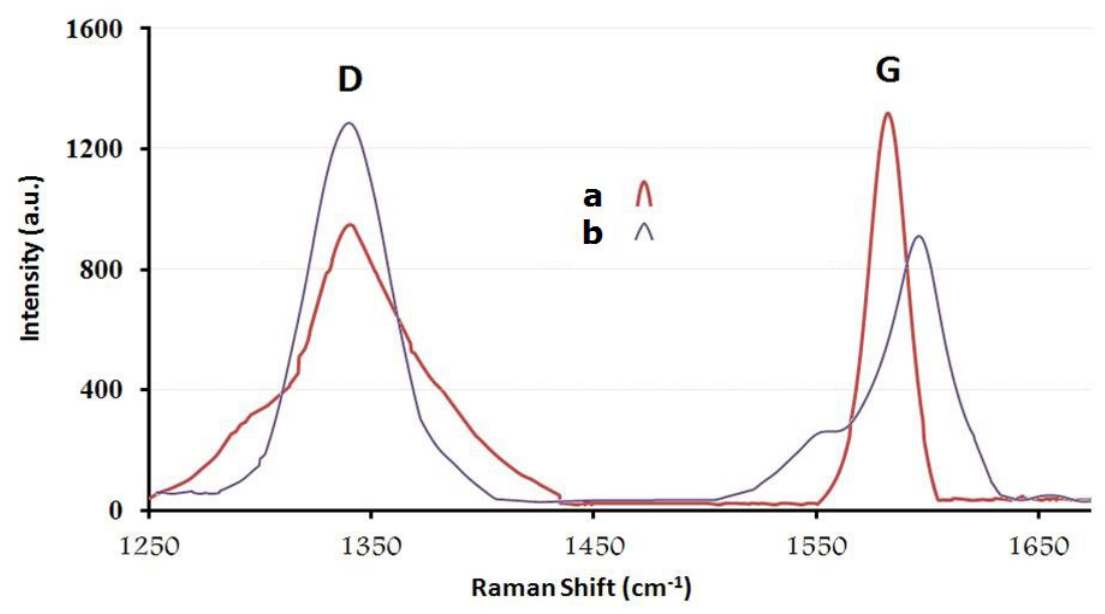

Fig. 2. Raman spectrum: (a) Graphene (b) Graphene / activated carbon composite. 


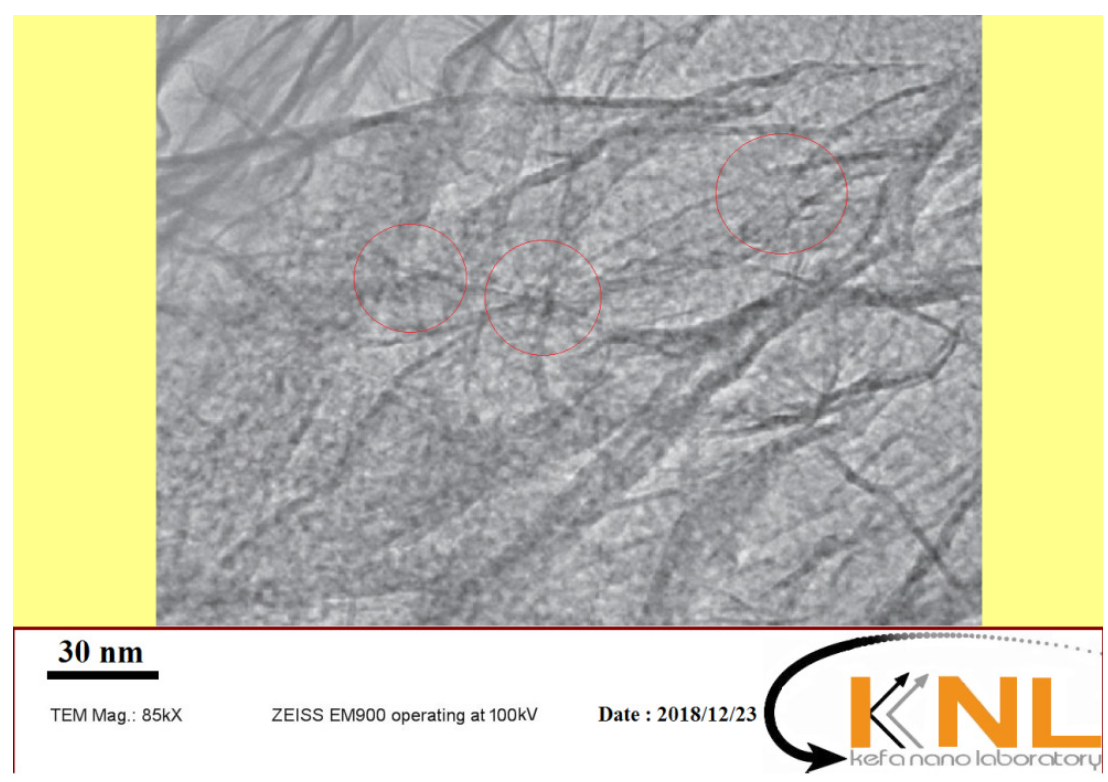

Fig. 3. TEM image of graphene/active carbon composite.

layered structure of graphene nanosheet, which has a micro-length, is well opened, and active carbon particles are interacting. Small graphene layers are randomly and irregularly distributed in activated carbon particles.

Moreover, in circular shapes, in addition to carbon, they also interact with each other, which have created a structural network in activated carbon and produced a total porosity. Moreover, this phenomenon is due to a large amount of disruption in the open graphene layers during the Hammers process which is linked by functional groups in the edges and structural defects of graphene to activated carbon. The very narrow channels created by the graphene plates inside the activated carbon structure cause large structural porosity of the composite to be obtained. To investigate the structural porosity of synthesized composites, the technique of nitrogen absorption and desorption under different relative pressures has been used by the BET method. In this research, the Belsorp mini
II BET device, the Japanese company BelJapan, has been used. Preparation of samples is including drying and degassing, which for this purpose, the specimens should be heated in vacuum at $120^{\circ} \mathrm{C}$ for 10 to 15 minutes for removing water vapor, carbon dioxide, or other molecules that may occupy the volume of the material cavities. Then the samples cool down to the liquid temperature of the nitrogen gas. Then the amount of nitrogen gas absorbed by the composite or graphene structure is measured by gradually increasing the relative pressure, and its depletion rate is calculated by decreasing the pressure at a constant temperature of $77 \mathrm{~K}$. It has been observed that in each case, with an increase in relative pressure, the nitrogen uptake has increased, and in the depletion mode, the same initial pattern of absorbed nitrogen volume has been obtained. The summary of the results is presented in Table 1. According to the Table 1, graphene has shown an increase in the specific surface area of activated carbon by $87 \%$. Also, the graphene composite with

Table 1. pores status analysis based on BET analysis results.

\begin{tabular}{llcccc}
\hline Structure & $\begin{array}{c}\text { Isotherm absorption } \\
\text { type }\end{array}$ & $\begin{array}{c}\text { Specific surface } \\
\text { area }(\mathrm{m} 2 / \mathrm{g})\end{array}$ & $\begin{array}{c}\text { Average pore } \\
\text { diameter (nm) }\end{array}$ & $\begin{array}{c}\text { Mesoporous (\%) } \\
\text { volume }\end{array}$ & $\begin{array}{c}\text { Total pore } \\
\text { volume }\end{array}$ \\
\hline Hammers graphene & Type I absorption & 61 & 37.6 & 30 & 0.37 \\
Activated carbon & Type II absorption & 982 & 8.2 & 8 & 2.45 \\
Graphene composite & Type IV absorption & 1841 & 5.6 & 9 & 2.91 \\
\hline
\end{tabular}


a specific surface area of $1841 \mathrm{~m} 2 / \mathrm{g}$ exhibits a very active surface structure that is very attractive in the absorption region. In addition, the process of synthesis of graphene composites has increased the volume of activated carbon cavities up to $18 \%$, indicating an increase in the absorption capacity of this structure. However, the size of the cavities is not larger and, as a result, the number of each of them is much larger. The presence of graphene in the active carbon structure reduces the size of the cavities, so that the average diameter of the cavities in the composite is reduced by $22 \%$. In other words, the hypothesis of the interaction between graphene and activated carbo $n$ on each other in the composite structure is visible from the point of view of the positive effect of graphene on the active carbon structure and graphene reduces the size of the cavities and increases their number in the activated carbon structure. Based on the results of the structural analysis of synthesized composite, which indicates the proper position of this structure as a sorbent, it is further used to absorb arsenic in water.

\subsection{The evaluation system of absorbent performance and process variables}

In this study, a batch reactor system has been used in a laboratory scale to carry out the process of adsorption and removal of arsenic in water, the schematic illustration is shown in Fig. 3.

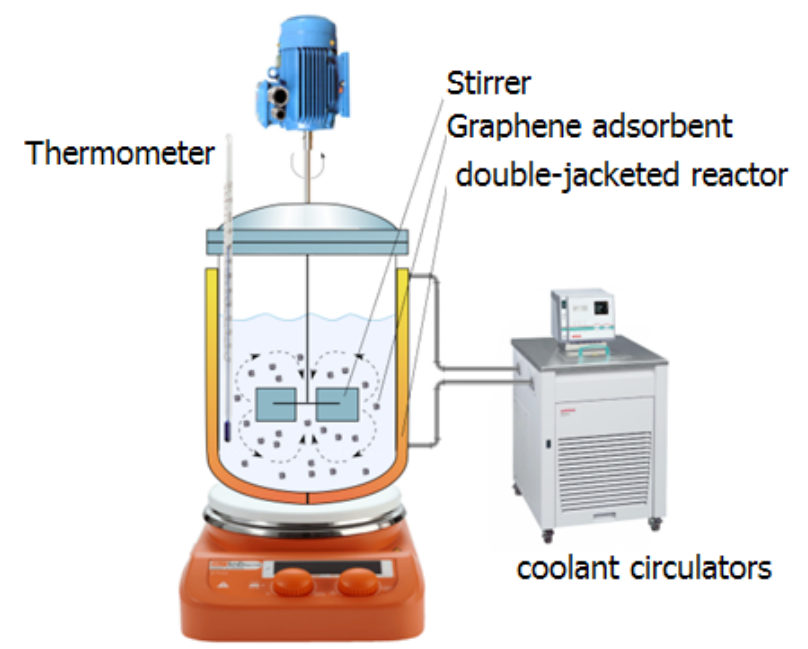

Fig. 4. Schematic of the absorption reactor system.
In accordance with Fig. 4, the system, which has been used, consists of a double-headed reactor of Pyrex with an internal volume of $300 \mathrm{cc}$, which is an environment for an adsorption reaction. During the absorption process, a circulator has been used to transfer the required temperature and to maintain the flow of the agent into the reactor's second wall. The reactor is equipped with a mechanical agitator system that can control the speed of the stirrer in different periods. At the end of the stirrer rod, two parallel blades, with $2 \mathrm{~cm}$ in length, are placed at an angle of $1 \mathrm{~cm}$ above the bottom of the reactor, which is made of polymer and neutral, with the aim of mixing the wastewater and the lack of deposition of the adsorbent at the end of the container is used during the absorption process. Also, this system provides an opportunity to study the rate of mixing speed in the absorption process. To provide the required heating, a magnetic stirrer equipped with an electric heater can also be used. Arsenic adsorption process for two active carbon adsorbents and graphene/activated carbon composite for $200 \mathrm{cc}$ wastewater containing threevalence arsenic $\left(\mathrm{Al}^{3+}\right)$ in water at $45{ }^{\circ} \mathrm{C}$ with an abrasive stirrer $700 \mathrm{rpm}$ has been carried out, and their results have been compared with each other. These processes have been repeated at different times and at different concentrations of arsenic in water and different concentrations of adsorbent and $\mathrm{pH}$ values. These values are presented in Table 2.

\section{Results and discussion}

According to the variables defined, the arsenic adsorption process is performed by two adsorbents including active carbon and active carbon-graphene composite in two $\mathrm{pH}$ values. In these experiments, the amount of adsorbent is used, and the time of the adsorption process with the initial concentration of arsenic in the wastewater is changed in two levels. Upon completion of the test, the amount of arsenic in the wastewater is measured by atomic absorption analysis with the PerkinElmer 2380 machine. The amount of adsorption of arsenic after the adsorption process is calculated by the following equation (Eq. 1). 
Table 2. The absorption Process Variables.

\begin{tabular}{llll}
\hline Number of variables & Non-dependent variable & Low variation level & High Level of variation \\
\hline 1 & concentration of absorbers $(\mathrm{mg})$ & 100 & 200 \\
2 & time of adsorption & 60 & 120 \\
3 & Amount of absorbent (mg As / L) & 100 & 200 \\
4 & $\mathrm{pH}$ & 3 & 6 \\
\hline
\end{tabular}

$\mathrm{qe}=(\mathrm{C} 0-\mathrm{Ce}) \cdot \mathrm{V} / \mathrm{m}$

(Eq.1)

where $q_{e}$ is the amount of absorption after reaching the equilibrium state with unit $\mathrm{mg} / \mathrm{g}, \mathrm{C}_{0}$ and $\mathrm{C}_{\mathrm{e}}$ are the initial and final concentrations of arsenic in the wastewater, which their units are $\mathrm{mg} / \mathrm{L}$, obtained by atomic absorption analysis and $\mathrm{V}$ is the volume of wastewater used per Liter, and $\mathrm{m}$ is the absorbent weight used in grams. Then based on the initial concentration of arsenic in the wastewater, the efficiency of arsenic adsorption is calculated. The absorbent absorption efficiency is obtained using the following equation (Eq. 2):

$\%$ Removal $=(\mathrm{C} 0-\mathrm{Ce}) / \mathrm{C} 0 \times 100$

Table 2 summarizes the number and conditions of absorption experiments. For more precision and the possibility of repeatability of the experiments, each experiment has been repeated three times, and its mean value as absorption efficiency has been calculated and reported. In addition, Table 3 summarizes the results of arsenic adsorption under various laboratory conditions.

According to Table 3, it is generally observed that the adsorption rate in activated carbon/graphene composites is higher than of activated carbon, so that under the same conditions due to the positive effect of graphene on porosity. The total amount of adsorption increased from $6.6 \%$ to $9.3 \%$, and the highest amount of arsenic adsorption occurred when using $200 \mathrm{mg}$ graphene/activated carbon composite in 120 minutes for effluent with concentration of $100 \mathrm{mg}$ which is $42.4 \%$. It is observed that increasing the concentration of arsenic in wastewater decreases the amount of absorption due to the presence of more arsenic in the wastewater

Table 3. The Summary of the results of arsenic adsorption under various laboratory conditions

\begin{tabular}{|c|c|c|c|c|c|c|c|c|}
\hline \multirow[b]{2}{*}{$\begin{array}{l}\text { Absorbent } \\
\text { type }\end{array}$} & \multirow{2}{*}{$\begin{array}{c}\text { The } \\
\text { amount of } \\
\text { adsorbent } \\
\text { (mg) }\end{array}$} & \multirow[b]{2}{*}{$\begin{array}{l}\text { Time of } \\
\text { absorption } \\
\text { (minute) }\end{array}$} & \multirow[b]{2}{*}{$\begin{array}{c}\text { Initial } \\
\text { concentration } \\
(\mathrm{mg} \mathrm{As} / \mathrm{L})\end{array}$} & \multirow[b]{2}{*}{$\begin{array}{c}\text { Absorption } \\
\text { Test } \\
\text { Conditions }\end{array}$} & \multicolumn{2}{|c|}{$\mathrm{pH}=6$} & \multicolumn{2}{|c|}{$\mathrm{pH}=3$} \\
\hline & & & & & $\begin{array}{l}\text { Absorption } \\
\text { rate }(\%)\end{array}$ & $\begin{array}{c}\text { Secondary } \\
\text { concentration } \\
(\mathrm{mg} \mathrm{As} / \mathrm{L})\end{array}$ & $\begin{array}{l}\text { Absorption } \\
\text { rate }(\%)\end{array}$ & $\begin{array}{c}\text { Secondary } \\
\text { concentration } \\
(\mathrm{mg} \mathrm{As} / \mathrm{L})\end{array}$ \\
\hline \multirow{8}{*}{ 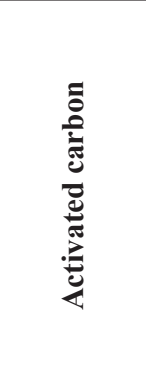 } & \multirow{4}{*}{$\overrightarrow{8}$} & \multirow{2}{*}{60} & 100 & $\mathrm{AC} 1$ & 79.2 & 79.2 & 74.4 & 74.4 \\
\hline & & & 200 & $\mathrm{AC} 2$ & 77.1 & 154.2 & 74.0 & 148.0 \\
\hline & & \multirow{2}{*}{120} & 100 & $\mathrm{AC} 3$ & 80.3 & 80.3 & 74.2 & 74.2 \\
\hline & & & 200 & $\mathrm{AC} 4$ & 79.7 & 159.4 & 76.4 & 152.8 \\
\hline & \multirow{4}{*}{$\stackrel{ }{8}$} & \multirow{2}{*}{60} & 100 & $\mathrm{AC5}$ & 86.4 & 86.4 & 80.2 & 80.2 \\
\hline & & & 200 & AC6 & 85.9 & 171.8 & 83.4 & 166.7 \\
\hline & & \multirow{2}{*}{120} & 100 & $\mathrm{AC} 7$ & 84.5 & 84.5 & 78.4 & 78.4 \\
\hline & & & 200 & $\mathrm{AC} 8$ & 86.6 & 173.2 & 83.3 & 166.6 \\
\hline \multirow{8}{*}{ 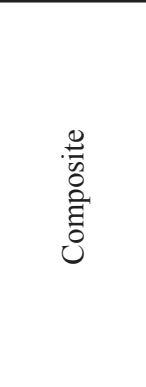 } & \multirow{4}{*}{100} & \multirow{2}{*}{60} & 100 & $\mathrm{AC} / \mathrm{G} 1$ & 83.8 & 83.8 & 77.6 & 77.6 \\
\hline & & & 200 & $\mathrm{AC} / \mathrm{G} 2$ & 82.2 & 164.4 & 79.1 & 158.2 \\
\hline & & \multirow{2}{*}{120} & 100 & $\mathrm{AC} / \mathrm{G} 3$ & 85.3 & 85.3 & 80.4 & 80.4 \\
\hline & & & 200 & $\mathrm{AC} / \mathrm{G} 4$ & 83.1 & 166.2 & 79.9 & 159.8 \\
\hline & \multirow{4}{*}{200} & \multirow{2}{*}{60} & 100 & $\mathrm{AC} / \mathrm{G} 5$ & 91.8 & 91.8 & 85.5 & 85.5 \\
\hline & & & 200 & AC/G6 & 90.7 & 181.4 & 87.6 & 175.2 \\
\hline & & \multirow{2}{*}{120} & 100 & $\mathrm{AC} / \mathrm{G} 7$ & 92.4 & 92.4 & 86.1 & 86.1 \\
\hline & & & 200 & $\mathrm{AC} / \mathrm{G} 8$ & 91.6 & 183.2 & 88.5 & 176.9 \\
\hline
\end{tabular}


and the creation of mass transfer resistance in its transfer to the absorbent level. In this case, by comparing the absorbance value for active carbon, the same phenomenon is observed, as the amount of adsorption decreases by about $2.5 \%$. Therefore, the amount of arsenic adsorption by active carbon with the presence of arsenic in large concentrations is inversely proportional, and it can be used as a supplementary method in adsorption. It can be seen that the presence of graphene in the activated carbon structure due to electron exchange in the sites at the edges and structural defects of graphene humors increases the absorption performance. However, the time of the absorption process does not have any significant effects on it, based on this study, if it is required to absorb less than $1 \%$ of arsenic in wastewater by using graphene/activated carbon, the time of absorption must be increased twice. In addition, if it is required to absorb less than $1 \%$ of arsenic in wastewater by using activated carbon, the time of absorption must be increased 2.3 times. As a result, graphene has increased the adsorption rate, which has accelerated the absorption process, and has a positive effect on the economy of this process. Therefore, due to the negligible difference and the very little effect of absorption time with the presence of graphene, the absorption time at
60 minutes as an optimal point of the process is suggested. By changing the amount of acidity of the effluent from 6 to 3 , the empirical values obtained in Fig. 2 are reported.

According to Fig. 5, it is observed that with increasing $\mathrm{pH}$ in all experiments, the amount of adsorption increases. Generally, it is seen that the reduction of the $\mathrm{pH}$ of the effluent is strongly influenced by the amount of absorption due to the competition of adsorption of arsenic in the acidic environment. In addition, it is observed that in lower $\mathrm{pH}$ values, the amount of adsorption decreases, but the intensity varies in different conditions. When only activated carbon adsorbent is used, the greatest effect of $\mathrm{pH}$ is on $\mathrm{AC} 3$ adsorption conditions, which changes $6.1 \%$ of absorption, whereas when composite absorbent is used, the most effect of $\mathrm{pH}$ is on $\mathrm{AC} / \mathrm{G} 7$ adsorption conditions, of which 6.3 units change the absorption percentage. In general, the maximum amount of arsenic adsorption decreased by $6.3 \%$, which is related to dilute arsenic concentrations when 200 $\mathrm{mg}$ of composite absorbent is taken at 60 and 120 minutes. Therefore, it is noted that the time of adsorption process has no significant effect on the amount of arsenic adsorption. To better evaluate the effect of time on adsorption, absorption processes

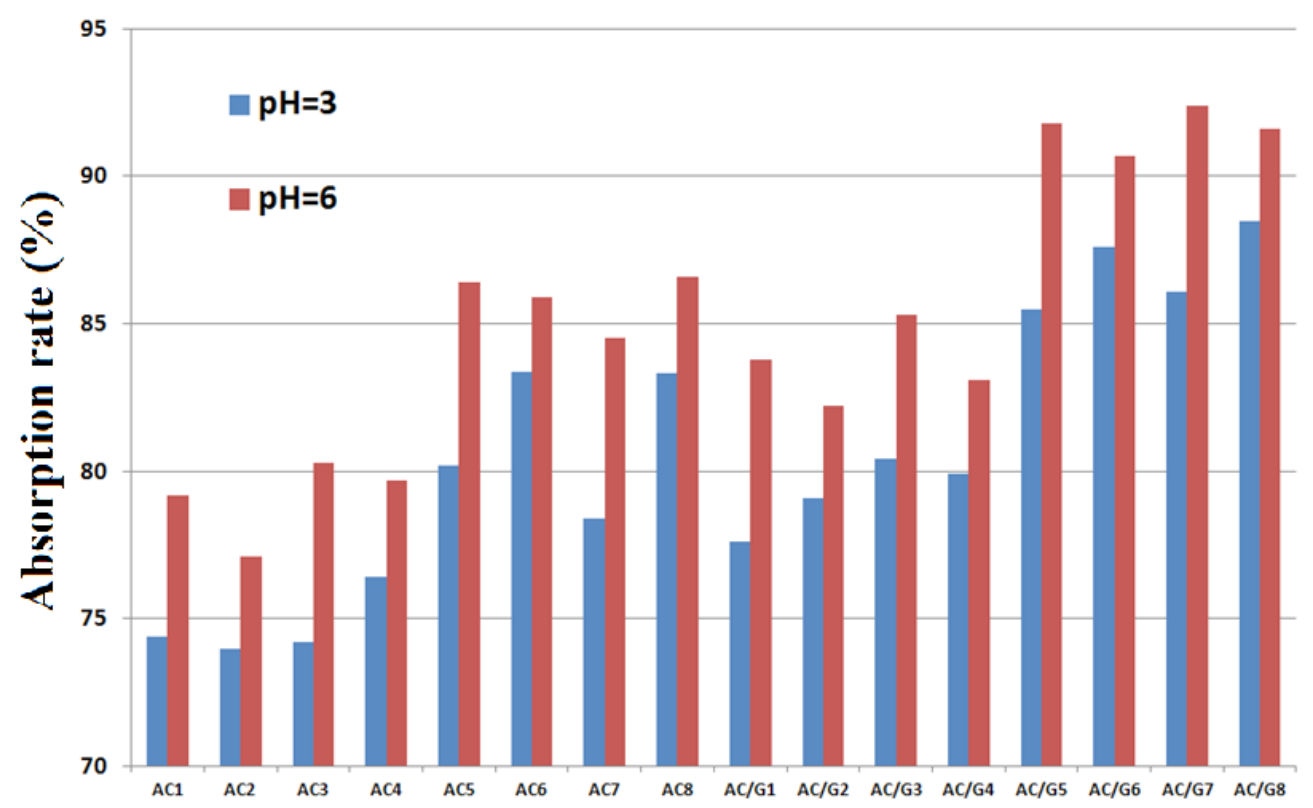

Fig. 5. Comparison of the effect of $\mathrm{pH}$ on arsenic removal under various laboratory conditions. 
Table 4. The Increasing adsorption of arsenic by the presence of graphene in the adsorbent structure.

\begin{tabular}{ccccc}
\hline $\begin{array}{c}\text { amount of adsorbent } \\
(\mathrm{mg})\end{array}$ & $\begin{array}{c}\text { Initial concentration } \\
(\mathrm{mg} \mathrm{As} / \mathrm{L})\end{array}$ & $\begin{array}{c}\text { Time of absorption } \\
(\mathrm{min})\end{array}$ & $\begin{array}{c}\mathrm{pH}=3 \\
\text { Increase in } \\
\text { absorption (\%) }\end{array}$ & $\begin{array}{c}\mathrm{pH}=6 \\
\text { Increase in } \\
\text { absorption (\%) }\end{array}$ \\
\hline 100 & 100 & 60 & 3.2 & 4.6 \\
100 & 200 & 60 & 5.1 & 5.1 \\
200 & 100 & 60 & 5.3 & 5.4 \\
200 & 200 & 60 & 4.2 & 4.8 \\
\hline
\end{tabular}

are compared with each other over a period of 60 minutes. According to Table 4, it is observed that in the same condition, the presence of graphene increases the amount of arsenic absorption.

According to Table 4, the presence of graphene in neutral $\mathrm{pH}(\mathrm{pH}=6)$ has a greater effect on the absorption rate due to the intrinsic effect of more graphene porosity on the total of the adsorbent. Moreover, the lack of ionic resistance in adsorption of arsenic could also point to the phenomenon of favorable spatial inhibition between graphene sheets in neutral media due to the negative charge found in the graphene agent groups of Hammers. That way, by increasing the $\mathrm{pH}$ of the environment, the presence of positive ions in the wastewater decreases, and the tendency to converge graphene plates in the composite weakens. As a result, adsorption of arsenic by composite adsorbent with less resistance and more surfaces by graphene is done. This subject occurs with the same intensity in the 120-minute adsorption period. Due to the presence of graphene in the structure of activated carbon, the effect of absorbing time is insignificant. In addition, due to the structural nature of the adsorbent and the low concentration of arsenic, better adsorption is there in the process. Therefore, it is observed that with the presence of less adsorbent, the greatest effect of $\mathrm{pH}$ in the adsorption process is due to the presence of graphene in the adsorbent structure which increases the absorption to about 1.4 times. That is, graphene greatly enhances the effect of the $\mathrm{pH}$ of the wastewater, in other words, when the composite absorbent is used, the sensitivity of the adsorption process to higher $\mathrm{pH}$ changes should be controlled with greater precision and be limited to higher $\mathrm{pH}$.

\section{4- Conclusion}

Activated carbon as one of the most suitable and efficient adsorbents in adsorption of arsenic in industrial effluents has a good performance, so that it can separate about $86.6 \%$ of arsenic from wastewater during 120 minutes. Because the adsorption process carried out by activated carbon is related to porosity and ion exchange, it is attempted to upgrade these parameters by changing its structure. For this purpose, the graphene structure of Hammers, which has a very high porosity and anionic surface charge, as a modern idea is used in this research. It has been observed that the presence of graphene in the adsorbent structure has caused a significant increase in the amount of adsorption of arsenic, so that in optimum conditions, the adsorption rate increased up to $91.8 \%$. On the other hand, the absorption time of more than 60 minutes have not had any significant effects on absorption, and this process causes the more economical due to requiring of shorter time for balancing the maximum absorption. Moreover, by observing the effect of wastewater $\mathrm{pH}$, graphene performance has been improved at higher $\mathrm{pH}$ values due to the force of dissolved ion potential difference at the rate of adsorption of arsenic by composite absorber. Therefore, it can be controlled by adjusting the $\mathrm{pH}$ of wastewater, and the use of corrected graphene structures easily controls the absorption process and increases the efficiency of absorption. Also, it has been observed that with increasing arsenic concentration, the absorbent performance of the composite is weakened. Due to the sensitivity of the presence of arsenic in released wastewater, these types of adsorbents are suitable for final purification and dilute wastewater. 


\section{References}

[1] M. A. P. Cechinel, A. A. U. de Souza, Study of arsenic adsorption onto activated carbon originating from cow bone, J. Clean. Prod., 65 (2014) 342-349.

[2] J. H. Park, Y. S. Han, J. S. Ahn, Comparison of arsenic co-precipitation and adsorption by iron minerals and the mechanism of arsenic natural attenuation in a mine stream, Water Res., 106 (2016), 295-303.

[3] L. R. Molinari, P. Argurio, Arsenic removal from water by coupling photocatalysis and complexationultrafiltration processes: A preliminary study, Water Res., 109 (2017) 327-336.

[4] B. Pakzadeh, J. R. Batista, Surface complexation modeling of the removal of arsenic from ionexchange waste brines with ferric chloride, J. Hazard. Mater., 188 (2011) 399-407.

[5] D. Santra, M. Sarkar, Optimization of process variables and mechanism of arsenic (V) adsorption onto cellulose nanocomposite, J. Mol. Liquids, 224 (2016) 290-302.

[6] O. P. Chen, Y. J. Lin, W. Z. Cao, C. T. Chang, Arsenic removal with phosphorene and adsorption in solution, Mater. Lett., 190 (2017) 280-282.

[7] A. Sigdel, J. Park, H. Kwak, P. Pyung-Kyu, Arsenic removal from aqueous solutions by adsorption onto hydrous iron oxide-impregnated alginate beads, J. Ind. Eng. Chem., 35 (2016) 277-286.

[8] A.A.H. Izzeldin, S.M. Bice, J. Catherine, O.N. Vincent, Adsorption studies of aqueous $\mathrm{Pb}(\mathrm{II})$ onto a sugarcane bagasse/multi-walled carbon nanotube composite, Phys. Chem. Earth 66 (2013) 157-166.

[9] R. Soni Dericks, P. Shukla, Data on Arsenic(III) removal using zeolite-reduced graphene oxide composite, Data in Brief, 22 (2019) 871-877.

[10] G. Zhao, X. Ren, X. Gao, X. Tan, J. Li, C. Chen, Y. Huang, X. Wang, Removal of $\mathrm{Pb}(\mathrm{II})$ ions from aqueous solutions on few-layered graphene oxide nanosheets, Dalton Trans., 40, (2011) 945-952.

[11] L. Cui, Y. Wang, L. Gao, L. Hu, L. Yan, Q. Wei, B. Du, EDTA functionalized magnetic graphene oxide for removal of $\mathrm{Pb}(\mathrm{II}), \mathrm{Hg}(\mathrm{II})$ and $\mathrm{Cu}(\mathrm{II})$ in water treatment: adsorption mechanism and separation property, Chem. Eng. J., 281 (2015) 1-9.

[12] Z. Goharibajestani, A. YudaYürüm, Effect of transition metal oxide nanoparticles on gas adsorption properties of graphene nanocomposites, Appl. Surface Sci., 475 (2019) 1070-1076.

[13] G. Zhao, J. Li, X. Ren, C. Chen, X. Wang, Few- layered grapheme oxide nano-sheets as superior sorbents for heavy metal ion pollution management, Environ. Sci. Technol., 45 (2011) 454-462,

[14] C. Zheng, X. Zhou, H. Cao, G. Wang, Z. Liu, Synthesis of porous graphene/activated carbon composite with high packing density and large specific surface area for supercapacitor electrode material, J. Power Sources, 258 (2014) 290-296.

[15] M. Sohail, M. Saleem, S. Noor Saeed, A. Afridi, M. Khan, M. Arif, Modified and improved Hummer's synthesis of graphene oxide for capacitors applications, Modern Elec. Mater., 3 (2017) 110116.

[16] A. Ganesan, M. M. Shaijumon, Activated graphenederived porous carbon with exceptional gas adsorption properties, Micropor. Mesopor. Mater., 220 (2016) 21-27. 